\title{
Determination of Salivary Myeloperoxidase, Immunoglobulin E, and Tumor Necrosis Factor-a after Complete Denture Insertion
}

\author{
Milena Kostic ${ }^{a}$ Marko Igic ${ }^{a}$ Tatjana Jevtovic Stoimenov $^{b}$ Ana Pejcic ${ }^{c}$ \\ Jana Pesic Stankovic ${ }^{d}$ \\ ${ }^{a}$ Department of Prosthodontics, Faculty of Medicine, University of Nis, Nis, Serbia; ${ }^{b}$ Department of Biochemistry,

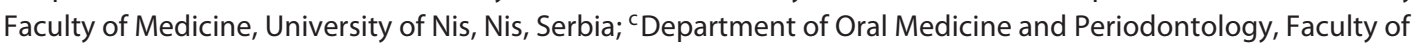 \\ Medicine, University of Nis, Nis, Serbia; ${ }^{d}$ Department of Microbiology, Faculty of Medicine, University of Nis, Nis, \\ Serbia
}

\section{Significance of the Study}

- Wearing complete dentures may cause allergic and traumatic reactions in the oral tissue, which could result in an increase in proinflammatory cytokines and salivary immunoglobulins in the saliva of the wearer. The increase in indicators of inflammation directly links acrylic dentures to oral inflammation.

\section{Keywords}

Complete dentures - Proinflammatory cytokines · Immunoglobulin E

\begin{abstract}
Objective: To detect activities of salivary myeloperoxidase (MPO) and concentrations of salivary tumor necrosis factor (TNF)-a as indicators of inflammatory reaction and salivary immunoglobulin E as an indicator of allergic reaction after complete insertion of acrylic dentures. Subjects and Methods: Complete dentures were made for a uniform group of elderly patients, and saliva samples were taken immediately before they were given to the patients, as well as 2, 3, 7, and 30 days after insertion of the dentures, with simultaneous monitoring of changes in the oral mucosa. Results: After 7 and 30 days of wearing upper and lower complete dentures, nonsignificant increases in salivary MPO and TNF-a were
\end{abstract}

\begin{tabular}{ll}
\hline KARGER & ( 2019 The Author(s) \\
& Published by S. Karger AG, Basel \\
E-Mail karger@karger.com & This article is licensed under the Creative Commons Attribution- \\
www.karger.com/mpp & $\begin{array}{l}\text { NonCommercial-NoDerivatives 4.0 International License (CC BY- } \\
\text { NC-ND) (http://www.karger.com/Services/OpenAccessLicense). } \\
\text { Usage and distribution for commercial purposes as well as any dis- } \\
\text { tribution of modified material requires written permission. }\end{array}$
\end{tabular}

proven to be indicators of inflammation. No changes were observed in the values of salivary immunoglobulin $\mathrm{E}$ during a 30-day observational period, which excluded the appearance of allergic reactions to acrylic materials in the tested group of patients. Conclusion: A nonsignificant increase in the levels of MPO was observed on day 7; it decreased after 30 days. TNF-a also tended to increase in a nonsignificant manner.

(C) 2019 The Author(s) Published by S. Karger AG, Basel

\section{Introduction}

Total tooth loss, as a consequence of hard dental tissue disease and periodontal disease, is especially common in elderly patients. According to the literature, complete denture insertion may be followed by allergic reactions to the acrylic materials that they are made of, as well as in- 
flammation of the oral tissue $[1,2]$. Wearing dentures may result in the appearance of different oral lesions, especially if the surface which touches the mucous tissue is large, which is the case with complete dentures [3]. Dental-related mucosal lesions are associated with denture plaque, weak retention and stability of the dentures, candida-associated denture stomatitis, and mechanical trauma of the tissue [4-6].

Candida albicans is a typical commensal microorganism of the oral cavity and it can become virulent in certain conditions and cause denture stomatitis, especially if there are local alterations in the mouth after the insertion of dentures. Denture stomatitis interrupts or completely disables the use of dentures, and inflammation of the mucous membrane is prolonged and followed by a burning feeling as well as a change in the taste of food. Thus, extensive local and systemic therapy is proposed [7].

Apart from denture stomatitis, which usually appears after prolonged wearing of dentures, all other complications are associated with the adaptation period immediately after the insertion of dentures [3, 8]. An analysis of changes in the oral tissue can be done by clinical observation and via methods such as real-time microscopy, which represents a noninvasive way of highlighting structural features of oral alterations at a microscopic level [9]. A possible allergic or traumatic reaction of the oral tissue against the presence of dentures in the mouth may be followed by an increase in proinflammatory cytokines and salivary immunoglobins in the saliva. Levels of these factors in the saliva of patients with complete dentures have not been reported.

Myeloperoxidase (MPO) is a heme-containing peroxidase expressed mainly in azurophilic granules of neutrophils and in the primary lysosomes of monocytes [10]. In the presence of hydrogen peroxide or a halide, MPO catalyzes the formation of reactive oxygen intermediates, thus significantly contributing to the antimicrobial effect of neutrophils $[11,12]$. In addition, MPO has been shown to be a mediator of local tissue damage and subsequent inflammation in different inflammatory diseases [13, 14].

Tumor necrosis factor (TNF)- $\alpha$ is an important mediator of inflammatory reactions and plays a key role in the pathogenesis of several serious inflammatory and autoimmune diseases. TNF- $\alpha$ is produced by monocytes and macrophages. The local cellular effect of TNF- $\alpha$ includes the adhesion of polymorphonuclear leukocytes to endothelial cells, degranulation of polymorphonuclear leukocyte, activation of phagocytes, and catabolic reactions of the extracellular matrix [15-18].
Immunoglobulin $\mathrm{E}$ (IgE) triggers reactions mediated by mastocytes and eosinophils. It is crucial in the defense against parasites and it is an indicator of allergic reactions [19]. Early hypersensitivity is characterized by a rapid release of fluid from blood vessels and mucus secretion, and it is often accompanied by inflammation [20]. An increase in the amount of salivary IgE could indicate acrylate hypersensitivity; therefore, allergic reactions could be the cause of inflammation of the oral tissue after complete denture insertion $[21,22]$.

The aim of this study was to measure the activity of salivary MPO and concentrations of salivary TNF- $\alpha$ as indicators of inflammation, and salivary IgE as an indicator of allergy, after complete acrylic denture insertion.

\section{Subjects and Methods}

This study included 6 male patients, aged 70-75 years (mean 72.33), who were not diagnosed with untreated systemic diseases, current infectious diseases, or changes in the oral mucosa. All of the patients were nonsmokers. The patients were inmates of an elderly care center, which implied they had the same lifestyle and diet, as well as similar health care. Two complete acrylic dentures (Triplex Hot; Ivoclar Vivadent, Lichtenstein), i.e., upper and lower, were indicated in all of the patients. All of the dentures were made and later corrected by the same dental therapist and dental technician. The patients were asked not to use their old dentures $48 \mathrm{~h}$ prior to the insertion of the new dentures. After the application and adaptation of the dentures in the mouth, the patients were advised regarding the use and maintenance of dentures, monitored by medical personnel. Control check-ups were scheduled 1,7 , and 30 days after the insertion of dentures in the patients. Oral lesions (erythema, traumatic irritations, or ulcers) were noted at each control check-up as recorded in the patients' files. Dentures were corrected in order to not prolong mechanical trauma.

Saliva ( $3 \mathrm{~mL}$ ) was collected between 8:00 and 10:00 a.m. immediately before insertion of the dentures and then 1,3 , and 30 days after the dentures were inserted.

The samples were immediately centrifuged at $12,000 \mathrm{~g}$ for 10 min in order to remove cells and microparticulate material. Clear supernatants were stored at $-20^{\circ} \mathrm{C}$.

\section{Determination of Enzymatic Activity of MPO}

Briefly, individual saliva samples were plated in 96-well flatbottomed tissue culture plates (NUNC; Roskilde, Denmark) previously filled with test substances at final concentrations of 0.5 , $1,5,10$, and $50 \mathrm{lM}$. The plates were incubated for $60 \mathrm{~min}$ at room temperature. The MPO activity was determined using 1,2-diaminobenzene (o-phenylenediamine) in citric buffer activated with $\mathrm{H}_{2} \mathrm{O}_{2}$ and Triton X-100. The reaction was stopped with $\mathrm{H}_{2} \mathrm{SO}_{4}$ solution $(1 \mathrm{M})$. Optical densities (OD) were determined in a Multiscan Ascent (Labsystems; Finland) at $540 \mathrm{~nm}$. The results are expressed as OD $(540 \mathrm{~nm})$. Each experiment was repeated 3 times. 
Table 1. Parameters examined during the study period

\begin{tabular}{llll}
\hline Period & $\begin{array}{l}\text { MPO, U/ } \mu g \\
\text { proteins in saliva }\end{array}$ & IgE, U/mL & TNF- $\alpha, \mathrm{pg} / \mathrm{mL}$ \\
\hline Before insertion & $3.452 \pm 1.886(2.975)$ & $0.301208 \pm 0.000029(0.301211)$ & $4.821 \pm 2.049(5.231)$ \\
1 day & $3.485 \pm 2.383(2.205)$ & $0.301222 \pm 0.000038(0.301208)$ & $4.797 \pm 3.337(3.030)$ \\
3 days & $3.405 \pm 1.592(3.075)$ & $0.301214 \pm 0.000034(0.301214)$ & $6.312 \pm 9.516(3.030)$ \\
7 days & $5.238 \pm 5.468(3.405)$ & $0.301251 \pm 0.000068(0.301246)$ & $7.726 \pm 4.006(7.879)$ \\
30 days & $3.270 \pm 0.873(3.515)$ & $0.301200 \pm 0.000028(0.301202)$ & $9.166 \pm 4.838(7.877)$ \\
\hline
\end{tabular}

Values are presented as means \pm SD (median).

Table 2. Clinical observation of oral lesions as a consequence of wearing complete dentures

\begin{tabular}{|c|c|c|c|c|c|c|c|c|c|c|c|c|c|}
\hline & Patient No. & \multicolumn{6}{|c|}{ After 3 days } & \multicolumn{6}{|c|}{ After 7 days } \\
\hline \multirow{2}{*}{ Upper dentures } & Traumatic irritation & - & + & - & + & - & - & + & - & + & - & + & + \\
\hline & Traumatic ulceration & - & - & - & - & - & - & - & - & - & + & - & - \\
\hline \multirow[t]{2}{*}{ Lower dentures } & Erythema & - & + & + & + & - & + & - & - & - & - & - & - \\
\hline & Traumatic ulceration & - & - & - & - & + & - & + & - & - & - & & - \\
\hline
\end{tabular}

Quantification of $\operatorname{IgE}$

Salivary IgE levels were quantitated in duplicate by sandwich ELISA using commercial kits (Radim; Pomezia, Italy). Salivary IgE levels were measured using standard samples with known levels of IgE provided by the manufacturer (expressed as IU/dL).

\section{Quantification of TNF- $\alpha$}

The concentrations of TNF- $\alpha$ were determined using human TNF- $\alpha$ ELISA kits (R\&D Systems; Minneapolis, MN, USA). The assay was performed according to the manufacturer's instructions (the results are expressed in $\mathrm{pg} / \mathrm{mL}$ ). The detection limit for TNF- $\alpha$ was $4.4 \mathrm{pg} / \mathrm{mL}$.

\section{Statistical Analyses}

The normality of the distribution of parameters was determined using the Shapiro/Wilk test; a comparison of values during the study period and values prior to denture insertion was made using a paired samples $t$ test and the Wilcoxon signed-rank test (if the data were not normally distributed). $p<0.05$ was considered statistically significant.

\section{Results}

The concentrations of MPO, TNF- $\alpha$, and IgE are shown in Table 1 . No statistically significant differences between the values of the tested parameters during the study period and prior to denture insertion were recorded. The mean values of MPO were higher after 7 days, and the mean levels of TNF- $\alpha$ were higher after 7 and 30 days (Table 1).

After a day of wearing complete dentures, mild erythemas were observed in the sublingual space. After a 30-day observational period, no oral mucosal lesions were noted in the mouth of the patients (Table 2).

\section{Discussion}

Wearing complete dentures may be the cause of mechanical oral lesions and an inflammatory reaction of the oral mucosa after insertion of dentures. This study started with the assumption that possible inflammatory changes on oral tissues after the application of complete dentures are followed by an increase in the concentrations of salivary MPO, TNF- $\alpha$, and IgE. Combining information on possible oral lesions in the mouth of patients with variations in the levels of these parameters was expected to shed light on the state of the oral tissue at the start of using dentures. 
The age of patients is associated with systemic diseases, nutritional deficiencies, polypharmacy, changes in the quality and quantity of saliva, and weak oral hygiene; this undoubtedly affects the outcome of treatment with complete dentures. Given that a decreased flow of saliva is common in elderly patients, mucosal ulcers and fungal infections are more frequent; thus, it is necessary for dentures to be fitted following the principles of good clinical practice and for them to be kept immaculately clean [23].

The group of patients included in this study was small $(n=6)$ but homogenous. The patients were of the same age, lived in the same conditions, and had the same diet, medical care, and surveillance. Female patients were excluded from this study because of the possibility of osteoporotic changes in the bones and untreated systemic diseases. The dentures were made by a dentist and a dental technician using materials from the same manufacturer. Regardless of the objective differences in each clinical case, the dentures had satisfactory retention and stabilization.

An accurate calculation of the sample size in the design of the study was not made, and thus the results can be considered preliminary but at the same time relevant as they were obtained from a homogeneous sample. Analysis of the biomolecular patterns of inflammation through a noninvasive examination such as a saliva analysis can provide a new approach for clinical and molecular diagnosis. Further studies will be needed to validate these preliminary results.

Uslu et al. [24] reported an increase in the level of MPO in the inflamed gingival tissue of a rat. TNF- $\alpha$ has been shown to be elevated in patients with oral leucoplakia [25], periodontitis [15] and recurrent apthous stomatitis [26].

No statistically significant differences in the values of the examined parameters during the tested period versus prior to denture insertion were observed. A slight increase was recorded in the level of MPO after 7 days of wearing dentures, followed by a gradual decrease until the end of the 30-day period. The levels of TNF- $\alpha$ exhibited a tendency to increase with the length of wearing dentures.

The appearance of oral mucosal lesions in the mouth of the patients was also monitored during the observational period. Erythema and traumatic irritations of the oral mucosa were recorded in the first 3 days of wearing complete dentures, which is considered common in clinical practice $[27,28]$. One of the patients had traumatic ulcers in the sublingual part of the lower jaw. The analysis of the patients' saliva did not show an increase in inflammatory parameters.
Traumatic irritations and ulcers were observed in all of the patients after 7 days of wearing dentures. Regardless of differences in the degree of severity and the localization of the resulting changes, the amount of MPO and TNF- $\alpha$ in the patients' saliva increased after 7 days, which could be associated with the intensity of the resulting changes in the oral cavity. Prolonged wearing of dentures emphasized their shortcomings; therefore, the correction was more extensive. It resulted in the absence of changes in the oral mucosa after 30 days, followed by a decrease in the level of MPO to initial values. A slight increase in salivary TNF- $\alpha$ could indicate a prolonged oral inflammation which might be associated with wearing dentures. Our results are similar to those from other studies, given the increase in salivary TNF- $\alpha$ in the first month after giving complete dentures to patients [15-17].

The absence of changes in the level of salivary IgE was related to the absence of early hypersensitivity to acrylic materials in the examined group of patients. However, some authors have reported allergic reactions to an unbound monomer of acrylic materials $[22,29,30]$.

Given the paucity of recent studies on inflammatory parameters in denture wearers in clinical conditions, a comparison of the obtained results with the published literature was not possible. On the other hand, a broad range of possibilities has been opened up for further research in this field, which will add to the conclusions reached in this study. Biochemical parameters are excellent markers of changes in oral tissues, so the study of the biochemistry of inflammatory patterns in the lesions of the oral cavity is of considerable importance for monitoring changes in oral mucosa in malignant transformations, which is of significance for clinical practice [31].

\section{Conclusion}

After 7 and 30 days of wearing upper and lower complete dentures, in a uniform group of patients, a nonsignificant increase in levels of salivary MPO and TNF- $\alpha$ were seen as indicators of inflammation. No changes were seen in the levels of salivary IgE during a 30-day observational period, which excludes the appearance of allergic reactions to acrylic materials in the tested group of patients.

\section{Acknowledgement}

This work was supported by an Internal Project (No. 11146294/11) of the Faculty of Medicine, University of Nis, Serbia. 


\section{Statement of Ethics}

This study was conducted in accordance with the Declaration of Helsinki, and ethical approval was granted by the Faculty of Medicine of the University of Nis. Each patient was informed about the aims and methods of this study, for which they gave their written consent.

\section{Disclosure Statement}

The authors declare no conflict of interests.

\section{References}

1 Lygre GB, Gjerdet NR, Grønningsaeter AG, Björkman L. Reporting on adverse reactions to dental materials-intraoral observations at a clinical follow-up. Community Dent Oral Epidemiol. 2003 Jun;31(3):200-6.

2 Kostic M, Pejcic A, Igic M, Gligorijevic N. Adverse reactions to denture resin materials. Eur Rev Med Pharmacol Sci. 2017 Dec;21(23): 5298-305.

3 Jainkittivong A, Aneksuk V, Langlais RP. Oral mucosal lesions in denture wearers. Gerodontology. 2010 Mar;27(1):26-32.

4 Freitas JB, Gomez RS, De Abreu MH, Ferreira E Ferreira E. Relationship between the use of full dentures and mucosal alterations among elderly Brazilians. J Oral Rehabil. 2008 May; 35(5):370-4.

5 Coelho CM, Sousa YT, Daré AM. Denturerelated oral mucosal lesions in a Brazilian school of dentistry. J Oral Rehabil. 2004 Feb; 31(2):135-9.

6 Corrêa L, Frigerio ML, Sousa SC, Novelli MD. Oral lesions in elderly population: a biopsy survey using 2250 histopathological records. Gerodontology. 2006 Mar;23(1):48-54.

7 Di Stasio D, Lauritano D, Minervini G, Paparella RS, Petruzzi M, Romano A, et al. Management of denture stomatitis: a narrative review. J Biol Regul Homeost Agents. 2018 JanFeb;32(2 Suppl. 1):113-6.

8 Martori E, Ayuso-Montero R, Martinez-Gomis J, Viñas M, Peraire M. Risk factors for denture-related oral mucosal lesions in a geriatric population. J Prosthet Dent. $2014 \mathrm{Apr}$; 111(4):273-9.

9 Grassia V, Gentile E, Di Stasio D, Jamilian A, Matarese G, D’Apuzzo F, et al. In vivo confocal microscopy analysis of enamel defects after orthodontic treatment: A preliminary study. Ultrastruct Pathol. 2016 Nov-Dec; 40(6):317-23.

10 Aratani Y. Myeloperoxidase: its role for host defense, inflammation, and neutrophil function. Arch Biochem Biophys. 2018 Feb;640: $47-52$.

11 Klebanoff SJ. Myeloperoxidase. Proc Assoc Am Physicians. 1999 Sep-Oct;111(5):383-9.
12 Nauseef WM: The proper study of mankind. Clin Invest. 200;107:401-3.

13 Pasterkamp G, van der Laan SW, Haitjema S, Foroughi Asl H, Siemelink MA, Bezemer T, et al. Human Validation of Genes Associated With a Murine Atherosclerotic Phenotype. Arterioscler Thromb Vasc Biol. 2016 Jun; 36(6):1240-6.

14 von Scheidt M, Zhao Y, Kurt Z, Pan C, Zeng $\mathrm{L}$, Yang X, et al. Applications and Limitations of Mouse Models for Understanding Human Atherosclerosis. Cell Metab. 2017 Feb;25(2): 248-61.

15 Özer Yücel Ö, Berker E, Mesci L, Eratalay K, Tepe E, Tezcan İ. Analysis of TNF-a (-308) polymorphism and gingival crevicular fluid TNF- $\alpha$ levels in aggressive and chronic periodontitis: A preliminary report. Cytokine. 2015 Apr;72(2):173-7.

16 Rossomando EF, Kennedy JE, Hadjimichael J. Tumour necrosis factor alpha in gingival crevicular fluid as a possible indicator of periodontal disease in humans. Arch Oral Biol. 1990;35(6):431-4.

17 Oates TW, Graves DT, Cochran DL. Clinical, radiographic and biochemical assessment of IL-1/TNF-alpha antagonist inhibition of bone loss in experimental periodontitis. J Clin Periodontol. 2002 Feb;29(2):137-43.

18 Graves DT, Delima AJ, Assuma R, Amar S, Oates T, Cochran D. Interleukin-1 and tumor necrosis factor antagonists inhibit the progression of inflammatory cell infiltration toward alveolar bone in experimental periodontitis. J Periodontol. 1998 Dec;69(12):1419-25.

19 He JS, Narayanan S, Subramaniam S, Ho WQ, Lafaille JJ, Curotto de Lafaille MA. Biology of IgE production: IgE cell differentiation and the memory of IgE responses. Curr Top Microbiol Immunol. 2015;388:1-19.

20 Ivković-Jureković I. Oral allergy syndrome. Acta Med Croatica. 2014 Jun;68(3):283-7.

21 Gawkrodger DJ. Investigation of reactions to dental materials. Br J Dermatol. 2005 Sep; 153(3):479-85.
22 Koutis D, Freeman S. Allergic contact stomatitis caused by acrylic monomer in a denture. Australas J Dermatol. 2001 Aug;42(3):203-6.

23 Diaz-Arnold AM, Marek CA. The impact of saliva on patient care: A literature review. J Prosthet Dent. 2002 Sep;88(3):337-43.

24 Uslu MÖ, Eltas A, Marakoğlu İ, Dündar S, Şahin K, Özercan İH. Effects of diode laser application on inflammation and mpo in periodontal tissues in a rat model. J Appl Oral Sci. 2018 Jul;26(0):e20170266.

25 Brailo V, Vucićević-Boras V, Cekić-Arambasin A, Alajbeg IZ, Milenović A, Lukac J. The significance of salivary interleukin 6 and tumor necrosis factor alpha in patients with oral leukoplakia. Oral Oncol. 2006 Apr;42(4): 370-3.

26 Boras VV, Lukac J, Brailo V, Picek P, Kordić D, Zilić IA. Salivary interleukin-6 and tumor necrosis factor-alpha in patients with recurrent aphthous ulceration. J Oral Pathol Med. 2006 Apr;35(4):241-3.

27 Celebić A, Knezović-Zlatarić D, Papić M, Carek V, Baucić I, Stipetić J. Factors related to patient satisfaction with complete denture therapy. J Gerontol A Biol Sci Med Sci. 2003 Oct;58(10):M948-53.

28 da Conceição Araújo MM, Martins MR, Dos Santos Soares AR, de Abreu Carvalho LR, Gomes VE, E Ferreira EF, et al. Relationship Between Quality of Complete Dentures and User Satisfaction at 1 and 5 Years Postinsertion. Int J Prosthodont. 2018 May/Jun;31(31): 271-9.

29 Rashid H, Sheikh Z, Vohra F. Allergic effects of the residual monomer used in denture base acrylic resins. Eur J Dent. 2015 Oct-Dec;9(4): 614-9.

30 Vaswani R, Kim SJ, Sanchez A, Vaswani S. Contact allergy to dimethacrylate. Cutis. 2012 Jan;89(1):10-2.

31 Giannelli G, Milillo L, Marinosci F, Lo Muzio L, Serpico R, Antonaci S. Altered expression of integrins and basement membrane proteins in malignant and pre-malignant lesions of oral mucosa. J Biol Regul Homeost Agents. 2001 Oct-Dec;15(4):375-80. 